\title{
The importance of finding the murderer!
} \author{
and Antonio M. Calafiore, MD
}

Michele Di Mauro, MD, PhD, ${ }^{a}$ Massimiliano Foschi, MD, ${ }^{b}$ Fabrizio Tancredi, MD, ${ }^{b}$ Gerardo Liberti, MD,

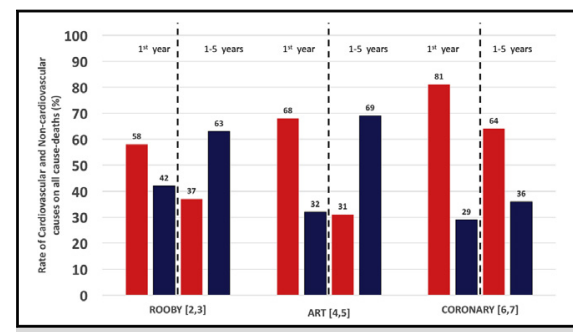

Rates of cardiovascular (red) and noncardiovascular (blue) deaths in 3 important trials.

Central Message

The knowledge of causes of death after surgery is essential to adopt preventive and therapeutic strategies to reduce the cardiovascular risk burden of patients where and when possible.

See Article page 54 2014. The conclusions assign the label of "murderer" to cardiovascular causes within the first year after CABG, whereas deaths attributed to noncardiovascular causes gained importance with time elapsed since CABG.

The strengths of this study are certainly the completeness of data and the large sample size (37,495 cases). The proportion of cardiovascular fatal events reported by Butt and colleagues ${ }^{1}$ represents roughly $53 \%$ of all causes, which is a bit lower than the proportions reported in most recent large trials, ${ }^{2-7}$ in which the rate of cardiovascular deaths at 1 -year follow up varied from $59 \%{ }^{2}$ to as high as $81 \%,{ }^{6}$ regardless of surgical strategy adopted (on-pump vs offpump, bilateral vs single internal thoracic artery). The trend throughout follow-up of the proportions of cardiovascular deaths among patients undergoing isolated CABG is controversial, however, because some experiences ${ }^{2-5}$ agree with the data reported by Butt and coworkers, ${ }^{1}$ yet others show a completely different scenario, with cardiovascular deaths outweighing noncardiovascular deaths both within 1-year follow-up and thereafter. ${ }^{6,7}$ In both the Randomized On/Off Bypass (ROOBY) trial ${ }^{2}$ and the Arterial Revascularization Trial (ART), ${ }^{4}$ cardiovascular deaths were prevalent within the first postoperative year $(59 \%$ and $69 \%$, of all deaths, respectively) falling to $38 \%,{ }^{3}$ and $31 \%,{ }^{5}$ of all-cause deaths in the period of 1 to 5 postoperative years. Conversely, in the CABG Off or On Pump Revascularization Study (CORONARY), in which the initial rate of cardiovascular deaths was very high $(81 \%$ of all-cause deaths), the proportion of cardiovascular deaths with reference to all-cause deaths continued to be greater than half with time: $81 \%$ within the first postoperative year $^{6}$ and $64 \%$ during the period of 1 to 5 postoperative years $^{7}$ (Figure 1).

Hercule Poirot, one of the most popular characters of Agatha Christie's novels, stated in Death in the Clouds, "There are more important things than finding the murderer." ${ }^{8}$ In our job, however, identifying the causes of death after surgery, both soon and thereafter, is essential if we are to adopt preventive and therapeutic strategies to reduce the cardiovascular burden on patients where and when possible.

To achieve this goal, the results of the study of Butt and coworkers $^{1}$ deserve a more detailed evaluation. Giving a glance to their mortality curves, it can be seen that the main divergence between cardiovascular and noncardiovascular causes occurs by the first postoperative month, rather than by the first year. It is plausible that there is a higher risk of death during the first postoperative month from myocardial infarction, arrhythmias, or a worsening of heart failure compared with death by cancer, which seems to be the most frequent noncardiovascular cause, ${ }^{1}$ as has also been reported by others. ${ }^{4,6,9}$

In the CORONARY trial, ${ }^{4}$ among 195 cardiovascular deaths at 1 year, $119(61 \%)$ occurred within the first 30 days, whereas 76 cardiovascular deaths occurred between the 30-day and 1-year follow-ups. The most common cause underlying cardiovascular death remains myocardial infarction, which occurs mainly during the first postoperative month. ${ }^{4,6}$ In the ART, the 1-year rate of myocardial infarction was $1.6 \%$; the early rate was $1.4 \%$, and the rate between 30 days and 1 year was $0.2 \%$. 


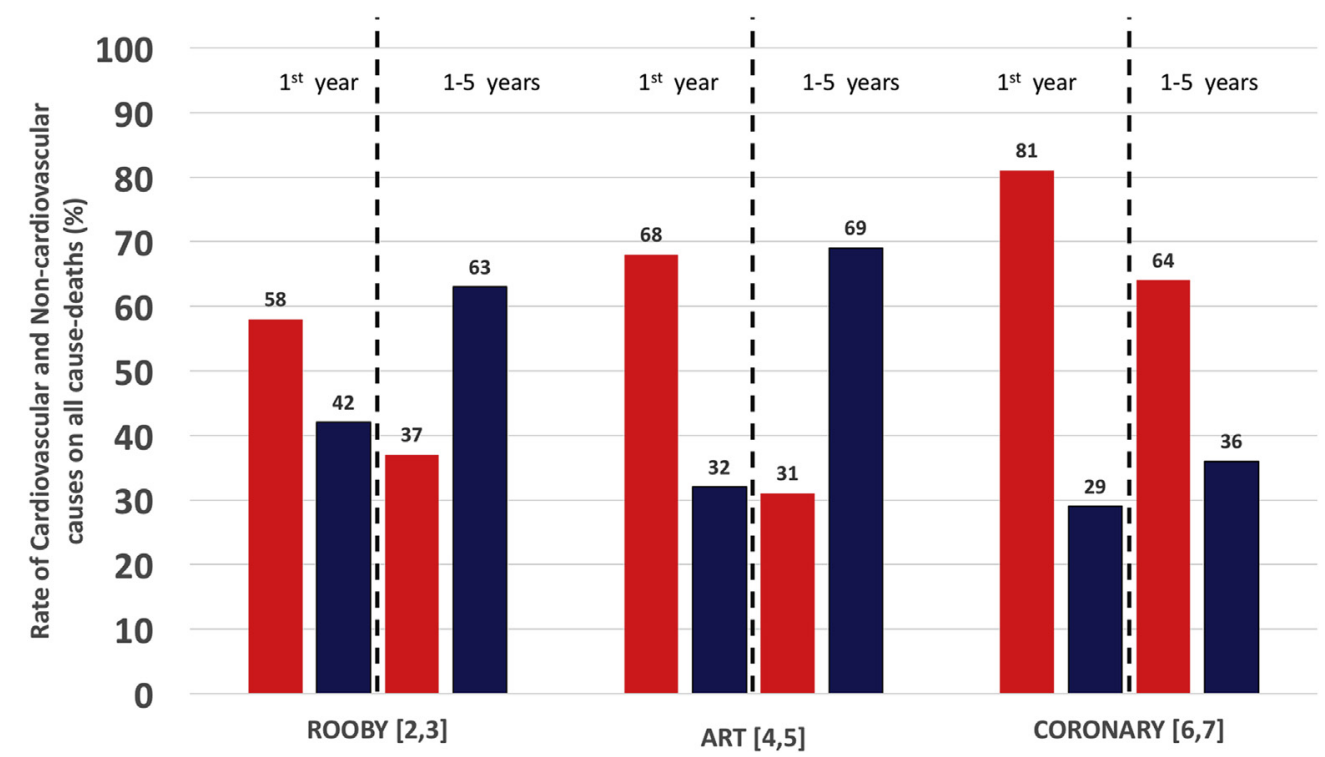

FIGURE 1. The rates of cardiovascular (red columns) and noncardiovascular (blue columns) causes as percentages of all-cause deaths in 3 important trials: the Randomized On/Off Bypass (ROOBY) trial, ${ }^{2,3}$ the Arterial Revascularization Trial (ART), ${ }^{4,5}$ and the CABG Off or On Pump Revascularization Study (CORONARY). ${ }^{6,7}$

This first key point is useful if we are to understand better how to manage the perioperative phase to reduce the burdens of postoperative myocardial infarction, heart failure, and arrhythmias, which are the most common cardiac causes of death: improving preoperative cardiac evaluation (ischemic cardiomyopathy? extent of myocardial scar? arrhythmogenic risk? history of heart failure?), improving operative management (take care to achieve a good myocardial protection, intraoperative graft control, reduce cardiopulmonary bypass time as much as possible), and finally administering a tailored, optimized therapy on the basis of the preoperative profile of every single patient. From this point of view, the hypothesis of using a double antiplatelet therapy after CABG, as for percutaneous coronary intervention, is emerging; it is endorsed by such studies as the very recent meta-analysis by Agarwal and coworkers, ${ }^{10}$ which included 8 randomized, controlled trials and 9 observational studies with a total of 11,135 patients. In this meta-analysis, double antiplatelet therapy was associated with reductions in graft occlusion and major adverse cardiac events, without a significant increase in major bleeding.

Another issue to be debated is the definition of cardiovascular death, because some studies ${ }^{5,11}$ split cardiac from vascular causes. In the Synergy between Percutaneous Coronary Intervention with Taxus and Cardiac Surgery (SYNTAX) study, ${ }^{9,11}$ cardiovascular causes were divided into cardiac causes (sudden cardiac deaths, myocardial infarction, progressive heart failure, and arrhythmia) and cardiac other causes (which included such other cardiac causes as cardiac tamponade and cardiac deaths with insufficient information for definitive classification), vascular causes (stroke, aortic dissection, and pulmonary embolism), and vascular other causes (major hemorrhage, peripheral embolism, and other). Among vascular causes, stroke is more liable to be linked to CABG, but this rationale holds mainly for early deaths. In the first month, stroke can be due to aortic manipulation or postoperative atrial fibrillation; for later stroke deaths, however, it is more difficult to elucidate a causal relationship. Similarly, perioperative pulmonary embolism and aortic dissection can be correlated to the operation, but between the first month and the first year, the role of vascular causes needs more detailed elucidation of mechanisms to allow intervention.

Finally, in the study of Butt and colleages, ${ }^{1}$ unknown causes were included among cardiovascular causes. Although such grouping is a frequent practice, it is really necessary to create a third section, as in the SYNTAX trial ${ }^{9}$ or the ART trial, ${ }^{5}$ to avoid any incorrect impact that these potentially noncardiovascular causes could have on the accurate assessment of cardiovascular causes.

\section{References}

1. Butt JH, Sørensen R, Bäck C, Olsen PS, Thorsteinsson K, Torp-Pedersen C, et al. Short- and long-term cause of death in patients undergoing isolated coronary artery bypass grafting: a nationwide cohort study. J Thorac Cardiovasc Surg. 2018;156:54-60.

2. Shroyer AL, Grover FL, Hattler B, Collins JF, McDonald GO, Kozora E, et al; Veterans Affairs Randomized On/Off Bypass (ROOBY) Study Group. On-pump versus off-pump coronary-artery bypass surgery. $N$ Engl J Med. 2009;361: 1827-37.

3. Shroyer AL, Hattler B, Wagner TH, Collins JF, Baltz JH, Quin JA, et al; Veterans Affairs ROOBY-FS Group. Five-year outcomes after on-pump and off-pump coronary-artery bypass. N Engl J Med. 2017;377:623-32. 
4. Taggart DP, Altman DG, Gray AM, Lees B, Gerry S, Benedetto U, et al; ART Investigators. Randomized trial of bilateral versus single internal-thoracicartery grafts. $N$ Engl J Med. 2016;375:2540-9.

5. Taggart DP, Altman DG, Gray AM, Lees B, Nugara F, Yu LM, et al; ART Investigators. Randomized trial to compare bilateral vs. single internal mammary coronary artery bypass grafting: 1-year results of the Arterial Revascularisation Trial (ART). Eur Heart J. 2010;31:2470-81.

6. Lamy A, Devereaux PJ, Prabhakaran D, Taggart DP, Hu S, Paolasso E, et al; CORONARY Investigators. Effects of off-pump and on-pump coronary-artery bypass grafting at 1 year. $N$ Engl J Med. 2013;368: $1179-88$.

7. Lamy A, Devereaux PJ, Prabhakaran D, Taggart DP, Hu S, Straka Z, et al; CORONARY Investigators. Five-year outcomes after off-pump or on-pump coronary-artery bypass grafting. N Engl J Med. 2016;375: 2359-68.

8. Christie A. Death in the Clouds (hardcover). London: Collins Crime Club; 1935: 256.

9. Milojevic M, Head SJ, Parasca CA, Serruys PW, Mohr FW, Morice MC, et al. Causes of death following PCI versus CABG in complex CAD: 5-year followup of SYNTAX. J Am Coll Cardiol. 2016;67:42-55.

10. Agarwal N, Mahmoud AN, Patel NK, Jain A, Garg J, Mojadidi MK, et al. Metaanalysis of aspirin versus dual antiplatelet therapy following coronary artery bypass grafting. Am J Cardiol. 2018;121:32-40.

11. Serruys PW, Morice MC, Kappetein AP, Colombo A, Holmes DR, Mack MJ, et al SYNTAX Investigators. Percutaneous coronary intervention versus coronary-artery bypass grafting for severe coronary artery disease. N Engl J Med. 2009;360:961-72. 